\title{
The Relationship between Body Appreciation Levels, Eating Attitudes and Physical Profiles of Turkish Elite Artistic Gymnasts
}

\author{
Pınar Tatlibal (Corresponding author) \\ Faculty of Sport Sciences, Dokuz Eylül University Necat Hepkon \\ Turabiye Mah. Beyler Cad. No. 4, Seferihisar, İzmir, Turkey \\ Tel: 90-553-203-30-00Ｅ-mail: pinartatlibal@hotmail.com
}

Received: November 5, 2021 Accepted: December 10, 2021

Published: December 31, 2021

doi:10.5296/jei.v7i3.19266

URL: https://doi.org/10.5296/jei.v7i3.19266

\begin{abstract}
Body dissatisfaction and disordered eating behavior in athletes may occur when sports and social pressures require an ideal body standard, if the athlete perceives that his or her body does not conform to this ideal. For this reason, the aim of this study is to investigate the relationship between artistic gymnasts' (AG) physical profiles, body appreciation levels and eating attitudes. A total of 32 elite AG (Turkish National Team), 13 women and 19 men, participated in this study. Height and body analyzes of the participants were measured. Body appreciation levels were determined by the Body Appreciation Scale (BAS), and eating attitudes were determined by the Eating Attitudes Test (EAT-26). With the Training Information Form, information about training frequencies and durations was provided. Comparative analyzes of the BAS and EAT-26 results of elite female and male gymnasts were performed. The physical profiles, eating attitudes and body appreciation levels of female AG were evaluated and the relationship between them was determined. While no significant correlation was found between the BAS, EAT-26 and physical profiles of the elite male AG, a negative significant correlation was found between the BAS and body mass index (BMI) of female elite AG $(\mathrm{p}<0.05)$. It was concluded that while BMI rates of elite female AG increased, their body appreciation levels decreased. The BAS results of elite AG' were found to be significantly higher than those of elite female AGs $(p<0.05)$.
\end{abstract}

Key words: Artistic gymnastics, Body appreciation, Eating attitudes, Physical profiles

\section{Introduction}

Gymnastics is one of the oldest sports branches that has continued its existence and 
development from the Olympic Games revived in 1986 until today's Olympic Games. Various disciplines of the gymnastics branch have developed over the years with different application forms. Today, gymnastics; It has six disciplines: artistic, rhythmic, trampoline, aerobics, acrobatic and parkour (FIG, 2021). The first discipline, also known as the basis of gymnastics, is artistic gymnastics.

In aesthetic sports such as gymnastics, weakness is seen as performance enhancing and therefore advantageous in competitive environments. Athletes with high body fat are expected to be less athletic and less successful (Smolak et al., 2000). Performance in all disciplines of gymnastics is associated with low fat ratios and high muscle mass. The fact that competition choreographies contain elegant and artistic components in many disciplines of gymnastics sports, and the necessity of both high performance and aesthetic presentation reveals the importance of physical appearance (Klentrou \& Plyley, 2003; Capdevila et al., 2005). For this reason, physical appearance is of great importance in gymnastics in terms of both performance and aesthetic presentation.

In general, it is emphasized that participation in competitive sports will increase the risk of eating disorders and disordered eating in athletes (Petrie et al., 2008; Sundgot-Borgen \& Torstveit, 2004). Especially female athletes who play aesthetic sports face great pressure from their parents, team members and coaches to restrict their food intake in order to achieve the aesthetic ideal of the technique and to maximize performance (Smolak et al., 2000; De Bruin et al., 2007). Body dissatisfaction and disordered eating behavior in athletes may occur when sports and social pressures require an ideal body standard, if the athlete perceives that his or her body does not conform to this ideal (Stice \& Shaw, 2002; Lester \& Petrie, 1995; Hargreaves \& Tiggemann, 2003). It has been reported that the formation and maintenance of eating disorders and irregular nutrition are directly related to body satisfaction (Jacobi et al., 2004). There are studies showing that the development of disordered eating in athletes is associated with body dissatisfaction (Krentz \& Warschburger, 2011; Byrne \& McLean, 2001). In lean sports, such as gymnastics or diving, where performance or success is influenced by a lean body shape, studies have found fairly consistent results showing that irregular diets have a higher prevalence rate for both men and women (Krentz \& Warschburger, 2011; Kong \& Harris, 2015; Reinking \& Alexander, 2005; Milligan \& Pritchard, 2006; Rousselet et al., 2017; Thiemann et al., 2015; Torstveit et al., 2008). Studies have found that constructs such as fear and guilt influence bulimic behavior, especially when tested with increased body dissatisfaction and dietary intent (Anderson et al., 2011; Greenleaf et al., 2010; Petrie et al., 2014).

At the same time, gymnastics education is the most basic education that develops physical education, which is very important not only for elite athletes, but also for the physical and mental development of children in pre-school period, school period and adolescence. Especially during adolescence, giving importance to physical appearance and aesthetic anxiety, which is common among young people, can have negative consequences. For this reason, it is thought that the subject is important for teachers who teach gymnastics.

It is thought that female gymnasts may be worried about looking thin and aesthetically 
beautiful and male gymnasts having a muscular body structure, which may lead to problems such as eating disorders and other undesirable health problems in the future. For this reason, the aim of this study is to investigate the relationship between AG' physical profiles, body appreciation levels and eating attitudes.

\section{Method}

\subsection{Participants}

A total of 32 elite artistic gymnasts (Turkish National Team), 13 women and 19 men, participated in this study, which aims to examine the relationship between physical profiles, body appreciation levels and eating attitudes.

\subsection{Procedure}

Height and body analyzes of the participants were measured. Body appreciation levels were determined by the Body Appreciation Scale (BAS), and eating attitudes were determined by the Eating Attitudes Test (EAT-26). The difference between the BAS and EAT-26 results of female and male elite AGs were analyzed. With the Training Information Form, information about training frequencies and durations was provided. The physical profiles, eating attitudes and body appreciation levels of female AG were evaluated and the relationship between them was determined.

The height of all participants was measured barefoot with an ultrasonic height meter (Langen Messstab 5003, Germany). Body weight, basal metabolic rate, body fat percentage, body mass index (BMI), muscle mass, body fluid ratio and bone mineral weight were measured on a body analysis scale (Tanita BC 401, Japan) in the morning on an empty stomach and without fluid intake.

Body appreciation levels of the participants were determined by the Body Appreciation Scale (BAS). The original BAS was created by Tylkaa and Wood-Barcalow (2015) to determine the body appreciation levels of individuals. The adaptation of the scale to Turkish was done by Anli et al. (2015). BAS is a scale consisting of 10 items and a single sub-dimension. The scale was prepared in a five-point Likert format as "1-Never 2-Rarely 3-Sometimes 4-Often 5-Always". There is no reverse item in the scale, and the lowest score that can be obtained from the scale is 10 , while the highest score is 50. A low score indicates a low level of body appreciation, and a high one indicates a high body appreciation (Tylkaa \& Wood-Barcalow, 2015; Anlı et al., 2015).

Eating habits of the participants were determined by applying the Eating Attitudes Test (EAT-26). EAT-26 was developed by Garner et al. (1982). For the EAT-26, 20 points is considered the cutoff point. A score of 20 or more is defined as "abnormal eating behavior", and values less than 20 points are defined as "normal eating behavior". The inventory was adapted into Turkish by Devran (2014) and used as a measurement tool in his study. However, EAT-26 alone does not provide a specific eating disorder diagnosis. Scores greater than 20 indicate further investigation by a qualified professional. Low scores (below 20) may still be consistent with severe eating problems, as denial of symptoms can be a problem in eating 
disorders. Results were interpreted with body weight history, current BMI and percent ideal body weight.

\subsection{Statistical Analysis}

SPSS 23.0 program (SPSS Inc., Chicago, IL) was used for statistical analysis of the study. Descriptive statistical analyzes were performed to determine the mean \pm standard deviation values of height, body analyzes, sport age, BAS and EAT-26 data. The difference between the BAS and EAT-26 results of female and male elite AGs was analyzed by Independent Sample $\mathrm{T}$ Test. Whether the data showed normal distribution or not was analyzed with the Shapiro-Wilk Test. The correlation analysis between the physical profiles, EAT-26 and BAS scores of the elite AG was performed separately for men and women. It was accepted as the level of significance $\mathrm{p}<0.05$.

\section{Results}

It was determined that 13 elite female AG participating in this study trained for a mean of 30 hours a week, 5 hours a day, 6 days a week. The descriptive analysis results of physical profiles, EAT-26 Scale and Body Appreciation Scale (BAS) scores of elite female artistic gymnasts are shown in Table 1.

Table 1. Descriptive analysis results of the physical characteristics, EAT-26 and BAS scores of elite female AG

\begin{tabular}{|l|l|l|l|}
\hline$(\boldsymbol{N}=\mathbf{1 3})$ & Mean \pm Std. Deviation & Max & Min \\
\hline Age (years) & $18.31 \pm 4.54$ & 31.00 & 13.00 \\
\hline Sports Age (years) & $11.39 \pm 3.51$ & 21.00 & 7.00 \\
\hline Body Weight (kg) & $51.48 \pm 6.97$ & 60.10 & 40.10 \\
\hline Height (cm) & $157.23 \pm 4.97$ & 164.00 & 146.00 \\
\hline BMI & $20.64 \pm 2.08$ & 23.70 & 16.90 \\
\hline Body Fat Ratio (\%) & $17.07 \pm 5.32$ & 24.10 & 8.00 \\
\hline Muscle Mass (kg) & $39.91 \pm 4.07$ & 46.70 & 33.20 \\
\hline Bone Mineral Weight (kg) & $2.14 \pm 0.24$ & 2.50 & 1.70 \\
\hline Basal Metabolic Rate (kcal) & $1310.23 \pm 117.71$ & 1504.00 & 1117.00 \\
\hline Body Fluid Ratio (\%) & $59.67 \pm 3.96$ & 67.00 & 55.00 \\
\hline EAT-26 & $14,31 \pm 6,79$ & 27.00 & 3.00 \\
\hline BAS & $37.77 \pm 7.03$ & 50.00 & 25.00 \\
\hline
\end{tabular}

Note. Mean \pm Std. Deviation: Mean \pm Standart Deviation; Max: Maximum value; Min: Minimum value; BMI: Body Mass Index; BAS: Body Appreciation Scale. 
It was determined that 19 elite male AG participants of this study trained for a mean of 24 hours a week, 4 hours a day, 6 days a week. The descriptive analysis results of the physical profiles, EAT-26 Scale and BAS scores of elite male artistic gymnasts are shown in Table 2.

Table 2. Descriptive analysis results of the physical characteristics, EAT-26 and BAS scores of elite male artistic gymnasts

\begin{tabular}{|l|l|l|l|}
\hline$(\boldsymbol{N = 1 9 )}$ & Mean \pm Std. Deviation & Max & Min \\
\hline Age (years) & $19.47 \pm 4.07$ & 28.00 & 14.00 \\
\hline Sports Age (years) & $13.05 \pm 3.41$ & 20.00 & 7.00 \\
\hline Body Weight (kg) & $62.93 \pm 9.63$ & 72.90 & 43.40 \\
\hline Height (cm) & $169.37 \pm 8.49$ & 184.00 & 156.00 \\
\hline BMI & $21.84 \pm 2.51$ & 26.40 & 16.30 \\
\hline Body Fat Ratio (\%) & $8.80 \pm 3.18$ & 14.80 & 5.00 \\
\hline Muscle Mass (kg) & $53.85 \pm 8.45$ & 63.80 & 36.20 \\
\hline Bone Mineral Weight (kg) & $2.87 \pm 0.40$ & 3.30 & 2.00 \\
\hline Basal Metabolic Rate (kcal) & $1699.53 \pm 233.23$ & 1975.00 & 1206.00 \\
\hline Body Fluid Ratio (\%) & $64.11 \pm 5.56$ & 77.20 & 52.20 \\
\hline EAT-26 & $10.95 \pm 6.23$ & 24.00 & 2.00 \\
\hline BAS & $45.37 \pm 4.86$ & 50.00 & 29.00 \\
\hline
\end{tabular}

Note. Mean \pm Std. Deviation: Mean \pm Standart Deviation; Max: Maximum value; Min: Minimum value; BMI: Body Mass Index; BAS: Body Appreciation Scale.

A comparison of the BAS and EAT-26 results of elite female and male gymnasts is shown in Table 3.

Table 3. Comparison of BAS and EAT-26 results of elite female and male gymnasts

\begin{tabular}{|l|l|l|l|l|l|}
\hline & & $\mathbf{N}$ & Mean \pm Std. Deviation & $\mathbf{t}$ & $\mathbf{p}$ \\
\hline \multirow{3}{*}{ BAS } & Female AG & 13 & $37.77 \pm 7.03$ & \multirow{2}{*}{-3.63} & \multirow{2}{*}{$\mathbf{0 . 0 1 *}$} \\
\cline { 2 - 5 } & Male AG & 19 & $45.37 \pm 4.86$ & \multirow{2}{*}{1.45} & \multirow{2}{*}{0.16} \\
\hline \multirow{2}{*}{ EAT-26 } & Female AG & 13 & $14.31 \pm 6.79$ & & \\
\cline { 2 - 5 } & Male AG & 19 & $10.95 \pm 6.23$ & \\
\hline
\end{tabular}


Note. N: Number of gymnast; Mean \pm Std. Deviation: Mean \pm Standart Deviation; BAS: Body Appreciation Scale; AG: Artistic gymnast. $* p<0.05$.

According to the Independent Sample T Test analysis results, the BAS value of the elite male $A G$ ' was found to be significantly higher than that of the female elite AG' (Table $3 ; p=0.01$ ).

Correlation analysis results of physical profiles, EAT-26 and BAS scores of elite female and male AG are shown in Tables 4 and 5.

Table 4. Correlation analysis results of physical profiles, EAT-26 and BAS scores of elite female AG

\begin{tabular}{|c|c|c|c|c|c|c|c|c|c|}
\hline$(N=13)$ & BW (kg) & BMI & BF (\%) & MM (kg) & BMW (kg) & BMR (kcal) & BFR (\%) & EAT-26 & BAS \\
\hline $\mathrm{H}(\mathrm{cm})$ & $.796^{* * *}$ & .520 & .408 & $.865^{* * *}$ & $.857^{* * *}$ & $.834^{* * *}$ & $-.636^{*}$ & .176 & -.139 \\
\hline BW (kg) & & $.927^{* * *}$ & $.777^{* *}$ & $.918^{* *}$ & $.922^{* *}$ & $.926^{* * *}$ & $-.912^{* * *}$ & .293 & -.533 \\
\hline BMI & & & $.857^{* * *}$ & $.780^{* * *}$ & $.799^{* * *}$ & $.801^{* * *}$ & $-.894^{* * *}$ & .311 & $-.647^{*}$ \\
\hline BF (\%) & & & & .487 & .541 & .501 & $-.924^{* * *}$ & .270 & -.496 \\
\hline MM(kg) & & & & & $.986^{* * *}$ & $.990^{* * *}$ & $-.698^{* * *}$ & .202 & -.421 \\
\hline BMW (kg) & & & & & & $.972^{* * *}$ & $-.720^{* * *}$ & .143 & -.391 \\
\hline BMR (kcal) & & & & & & & $-.703^{* * *}$ & .212 & .511 \\
\hline BFR (\%) & & & & & & & & .268 & .448 \\
\hline EAT-26 & & & & & & & & &.-442 \\
\hline
\end{tabular}

Note. H: Height; BW: Body Weight; BFR: Body Fat; MM: Muscle Mass; BMW: Bone Mineral Weight; BMR: Basal Metabolic Rate; BFR: Body Fluid Ratio; BAS: Body Appreciation Scale. *: Correlation is significant at the 0.05 level (2-tailed); **: Correlation is significant at the 0.01 level (2-tailed).

In the results of the correlation analysis of the physical profiles, EAT-26 and BAS scores of elite female AG', a statistically significant negative correlation was found between BAS and BMI values (Table $4 ; p=-.647$ ). It was concluded that while BMI rates of elite female AG increased, their BAS levels decreased. 


\section{Macrothink}

Table 5. Correlation analysis results of physical profiles, EAT-26 and BAS scores of elite male AG

\begin{tabular}{|c|c|c|c|c|c|c|c|c|c|}
\hline$(N=19)$ & BW (kg) & BMI & BF (\%) & MM (kg) & BMW (kg) & BMR (kcal) & BFR (\%) & EAT-26 & BAS \\
\hline H (cm) & $.729^{* * *}$ & .139 & -.207 & $.808^{* *}$ & $.733^{* * *}$ & $.790^{* * *}$ & -.214 & -.353 & -.012 \\
\hline BW (kg) & & $.778^{* * *}$ & .221 & $.948^{* *}$ & $.930^{* * *}$ & $.946^{* *}$ & $-.552^{*}$ & -.212 & .042 \\
\hline BMI & & & $.506^{*}$ & $.631^{* * *}$ & $.673^{* * *}$ & $.644^{* * *}$ & $-.607^{* * *}$ & .015 & .081 \\
\hline BF (\%) & & & & -.040 & -.053 & -.051 & $-.672^{* * *}$ & -.037 & .207 \\
\hline MM (kg) & & & & & $.959^{* * *}$ & $.987^{* *}$ & -.299 & -.258 & -.031 \\
\hline BMW (kg) & & & & & & $.989^{* *}$ & -.387 & -.313 & -.026 \\
\hline BMR (kcal) & & & & & & & -.351 & -.278 & -.041 \\
\hline BFR (\%) & & & & & & & & .231 & -.183 \\
\hline EAT-26 & & & & & & & & & -.372 \\
\hline
\end{tabular}

Note. H: Height; BW: Body Weight; BFR: Body Fat; MM: Muscle Mass; BMW: Bone Mineral Weight; BMR: Basal Metabolic Rate; BFR: Body Fluid Ratio; BAS: Body Appreciation Scale. *: Correlation is significant at the 0.05 level (2-tailed); **: Correlation is significant at the 0.01 level (2-tailed).

In the results of the correlation analysis of the physical profiles, EAT-26 and BAS scores of elite male AG', no statistically significant result was reached between the BAS and EAT-26 values and their physical profiles (Table 5).

\section{Discussion}

In this study, which aimed to investigate the relationship between physical profiles, body appreciation levels and eating attitudes of gymnasts, the mean EAT-26 and BAS scores of elite female AG were found to be $14.31 \pm 6.79$ and $37.77 \pm 7.03$, respectively. The EAT-26 mean of elite female AG' who train for an average of 30 hours a week was found below 20 points, that is, at the level of "normal eating behavior". Considering their BMI results $(20.64 \pm 2.08)$ and body weights $(51.48 \pm 6.97 \mathrm{~kg})$, which are in the normal range, female AG' are not considered to have an eating behavior disorder or to be prone to eating behavior disorder (Table 1). A negative significant correlation was found between BAS and BMI of female elite AG (Table 4; $\mathrm{p}=$-.647). It was concluded that while the BMI ratios of elite female AG increased, their body appreciation levels decreased. It was determined that 19 elite male AG participants in this study trained for an average of 24 hours a week, 4 hours a day, 6 days a week. The mean EAT-26 and BAS scores of elite male AG' were found to be $10.95 \pm 6.23$ and $45.37 \pm 4.86$, respectively. No significant correlation was found between the physical profiles, EAT-26 and BAS results of the elite male AGs (Table 5). Considering their BMI results $(21.84 \pm 2.51)$ and body weights $(62.93 \pm 9.63 \mathrm{~kg})$, which are in the normal range, 
male $\mathrm{AG}^{\prime}$ are not considered to have an eating behavior disorder or to be prone to eating behavior disorder (Table 2). In addition, the BAS levels of the elite male AG' were significantly higher than the female elite $\mathrm{AG}^{\prime}$ (Table $3 ; \mathrm{p}=0.01$ ).

Loland, 1999 emphasizes that the body perceptions of the athletes are related to the functionality and performance requirements in the sport they do. Aesthetic sports requires a weak body structure in order to perform the desired body difficulties and apparatus use in accordance with aesthetic standards. Athletes could be dissatisfied if they perceive a discrepancy between the own body shape and the perceived ideal body shape for best performance (Krentz \& Warschburger, 2011). It has also been reported that BMI may be a factor related to body dissatisfaction. A correlation between body dissatisfaction and BMI has been observed in both the general (Kantanista et al., 2017) and sports populations (DiGioacchino DeBate et al., 2002; Karr et al., 2013). Karr et al., 2013 found that higher BMI was associated with greater body dissatisfaction in female sports participants in different types of sports (aesthetic/slim, unaesthetic/lean, and unaesthetic/lean). In the results of this study, the correlation between BMI levels and BAS levels of elite female AG' in terms of increase in BMI levels and decrease in BAS levels was consistent with the literature (Krentz \& Warschburger, 2011; Kantanista et al., 2017; DiGioacchino DeBate et al., 2002; Karr et al., 2013) but such a result was not obtained in elite male AG.

Women have traditionally displayed a greater commitment to the pursuit of cultural standards of beauty than have men (Furnham et al., 2002). Davis and Cowles (1991) reported that dieting is a more common behavior among women than men, who report that how they feel about their body is as important as how they feel about themselves in general. During a time when having a slim body is valued for women, those for whom body satisfaction is a central element of self-esteem are more likely to preoccupy with weight and be prone to negative eating attitudes (Furnham et al., 2002). In this study, the BAS levels of the elite male AG' were found to be statistically significantly higher than the elite female AG', suggesting that women are more concerned about their bodies and is consistent with the literature (Furnham et al., 2002; Davis \& Cowles, 1991). However, body dissatisfaction is lower among athletes in all kinds of sports, including aesthetic sports, compared to non-athletic control groups (Hausenblas \& Downs, 2001; Smolak et al., 2000).

There is often a correlation between eating disorders and body image dissatisfaction. This has been demonstrated by the high prevalence of eating disorders in groups that should have an "ideal" body, such as ballet dancers and models, as well as athletes (Sundgot-Borgen, 1993; Garner \& Garfinkel, 1980). A high incidence of disordered eating is seen in elite sports where competitive results are dependent on referees' opinions and aesthetic judgment, as in gymnastics, figure skating, diving and dance (De Bruin et al., 2007; Sundgot-Borgen, 1994). Torstveit et al., 2008 found that elite athletes in sports where they should be thin had a more irregular diet, while body dissatisfaction was lower compared to other types of sports. This suggests that eating disorders in elite athletes in aesthetic sports do not occur more often because of a higher overall dissatisfaction with their own body (Reel et al., 2013).

According to the results of this study, no significant results were found between the eating 
habits and body appreciation levels of both female and male elite AGs. In addition, it has been determined that elite AGs with normal values in terms of physical characteristics have a high level of body appreciation. The BAS results of the male elite AG were found to be significantly higher than the elite female AG. In this study, no negative results were observed regarding the eating attitudes and body appreciation levels of the gymnasts in the Turkish National Team.

\section{Conclusion}

Artistic gymnastics is a sport where motor skills and technique must be applied in a high-level aesthetic manner. Maintaining ideal aesthetics and performance can be challenging for gymnasts at times. Body appearance, which is of great importance, is affected by the diet as well as the effects of training. Maintaining this balance is of great importance for the psychological and physiological health of gymnasts. In addition to well-planned training programs, a good nutrition program is absolutely essential for gymnasts. It is thought that it will be beneficial to conduct studies with a larger number of participants in the future.

The number of participants in this study is limited only to artistic gymnasts at the Turkish National Team level. It is thought that studies on this subject, which will be carried out with a high number of participants, are necessary for athletes and coaches.

\section{References}

Anderson, C. M., Petrie, T. A., \& Neumann, C. S. (2011). Psychosocial correlates of bulimic symptoms among NCAA Division-I female collegiate gymnasts and swimmers/divers. Journal of Sport and Exercise Psychology, 33(4), 483-505. https://doi.org/10.1123/ jsep.33.4.483

Anlı, G., Akın, A., Eker, H., \& Özçelik, B. (2015). The validity and reliability of Turkish version of the body appreciation scale. The Journal of Academic Social Science Studies, 36, 505-511. https://doi.org/10.9761/JASSS2906

Byrne, S., \& McLean, N. (2001). Eating disorders in athletes: A review of the literature. Journal of Science and Medicine in Sport, 4(2), 145-59. https://doi.org/10.1016/S1440-2440 (01)80025-6

Capdevila, L., Ninerola, J., \& Toro, J. (2005). Body mass index in female Spanish Olympic athletes. Percept Mot Skills, 100, 99-100. https://doi.org/10.2466/pms.100.1.99-100

Davis, C., \& Cowles, M. (1991). Body image and exercise: A study of relationships and comparisons between physically active men and women. Sex Roles: A Journal of Research, 25(1-2), 33-44. https://doi.org/10.1007/BF00289315

De Bruin A. K., Oudejans, R. R. D., \& Bakker, F. C. (2007). Dieting and body image in aesthetic sports: A comparison of Dutch female gymnasts and non-aesthetic sport participants. Psychology of Sport and Exercise, 8(4), 507-520. https://doi.org/10.1016/j.psychsport. 2006.10.002

Devran, S. B. (2014). Doğu Anadolu Bölgesinde yaşayan Adölesan ve Yetişkinlerin Beslenme 
Alışkanlıkları ile Yeme Tutum Davranışlarının Belirlenmesi (Yayımlanmamış yüksek lisans tezi, Başkent Üniversitesi Sağlık Bilimleri Enstitüsü, Ankara).

DiGioacchino DeBate, V., Wethington, H., \& Sargent, R. (2002). Subclinical eating disorder characteristics among male and female triathletes. Eating and Weight Disorders, 7(3), 210-220. https://doi.org/10.1007/BF03327459

FIG. (2021). Retrieved from https://live.gymnastics.sport

Furnham, A., Badmin N., \& Sneade I. (2002) Body Image Dissatisfaction: Gender Differences in Eating Attitudes, Self-Esteem, and Reasons for Exercise. The Journal of Psychology, 136(6), 581-596. https://doi.org/10.1080/00223980209604820

Garner, D. M., \& Garfinkel, P. E. (1980). Socio-cultural factors in the development of anorexia nervosa. Psychological Medicine, 10, 647-656. https://doi.org/10.1017/S00332917 00054945

Garner, D. M., Olmsted, M. P., Bohr, Y., \& Garfinkel, P. E. (1982). The eating attitudes test: psychometric features and clinical correlates. Psychological Medicine, 12(4), 871-878. https://doi.org/10.1017/S0033291700049163

Greenleaf, C., Petrie, T., Reel, J., \& Carter, J. (2010). Psychosocial risk factors of bulimic symptomatology among female athletes. Journal of Clinical Sport Psychology, 4(3), 177-90. https://doi.org/10.1123/jcsp.4.3.177

Hargreaves, D., \& Tiggemann, M. (2003). The effect of "thin ideal" television commercials on body dissatisfaction and schema activation during early adolescence. Journal of Youth and Adolescence, 32(5), 367-73. ttps://doi.org/10.1023/A:1024974015581

Hausenblas, H. A., \& Downs, D. S. (2001). Comparison of Body Image between Athletes and Nonathletes: A Meta-Analytic Review. Dy Image, Athletes Journal of Applied Sport Psychology, 13, 323-339. https://doi.org/10.1080/104132001753144437

Jacobi, C., Hayward, C., de Zwaan, M., Kraemer, H. C., \& Agras, W. S. (2004). Coming to terms with risk factors for eating disorders: Application of risk terminology and suggestions for a general taxonomy. Psychological Bulletin, 130(1), 19. https://doi.org/10.1037/ 0033-2909.130.1.19

Kantanista, M. K.-Z., Borowiec, J., \& Osinski, W. (2017). Is Underweight associated with more positive body image? Results of a cross-sectional study in adolescent girls and boys. Spanish Journal of Psychology, 20. https://doi.org/10.1017/sjp.2017.4

Karr, T. M., Davidson, D., Bryant, F. B., Balague, G., \& Bohnert, A. M. (2013). Sport type and interpersonal and intrapersonal predictors of body dissatisfaction in high school female sport participants. Body Image, 10(2), 210-219. https://doi.org/10.1016/j.bodyim.2012.11.001

Klentrou, P., \& Plyley, M. (2003). Onset of puberty, menstrual frequency, and body fat in elite rhythmic gymnasts compared with controls. Br J Sports Med, 37, 490-494. https://doi.org/ 10.1136/bjsm.37.6.490 
Kong, P., \& Harris, L. M. (2015). The sporting body: body image and eating disorder symptomatology among female athletes from leanness focused and nonleanness focused sports. The Journal of Psychology, 149(2), 141-60. https://doi.org/10.1080/00223980. 2013.846291

Krentz, E. M., \& Warschburger, P. (2011). Sports-related correlates of disordered eating in aesthetic sports. Psychology of Sport and Exercise, 12(4), 375-82. https://doi.org/10.1016/ j.psychsport.2011.03.004

Lester, R., \& Petrie, T. A. (1995). Personality and physical correlates of bulimic symptomatology among Mexican American female college students. Journal of Counseling Psychology, 42(2), 199. https://doi.org/10.1037/0022-0167.42.2.199

Loland, N. W. (1999). Some contradictions and tensions in elite sportsmen's attitudes towards their bodies. Sociology of Sport, 3, 291-302. https://doi.org/10.1177/101269099034003005

Milligan, B., \& Pritchard, M. (2006). The relationship between gender, type of sport, body dissatisfaction, self esteem and disordered eating behaviors in division I athletes. Athletic Insight, 8(1), 32-46.

Petrie, T. A., Galli, N., Greenleaf, C., Reel, J., \& Carter, J. (2014). Psychosocial correlates of bulimic symptomatology among male athletes. Psychology of Sport and Exercise, 15(6), 680-7. https://doi.org/10.1016/j.psychsport.2013.09.002

Petrie, T. A., Greenleaf, C., Reel, J., \& Carter, J. (2008). Prevalence of eating disorders and disordered eating behaviors among male collegiate athletes. Psychology of Men \& Masculinity, 9(4), 267. https://doi.org/10.1037/a0013178

Reel, J., Petrie, T. A., SooHoo, S., \& Anderson, C. M. (2013). Weight pressures in sport: Examining the factor structure and incremental validity of the weight pressures in sport-Females. Eating Behaviors, 14, 137-144. https://doi.org/10.1016/j.eatbeh.2013.01.003

Reinking, M. F., \& Alexander, L. E. (2005). Prevalence of disordered-eating behaviors in undergraduate female collegiate athletes and nonathletes. Journal of Athletic Training, 40(1), 47.

Rousselet, M., Gue'rineau, B., Paruit, M., Guinot, M., Lise, S., Destrube, B., ... Prétagut, S. (2017). Disordered eating in French high-level athletes: Association with type of sport, doping behavior, and psychological features. Eating and Weight Disorders-Studies on Anorexia, Bulimia and Obesity, 22(1), 61-8. https://doi.org/10.1007/s40519-016-0342-0

Smolak, L., Murnen, S. K., \& Ruble, A. E. (2000). Female athletes and eating problems: a meta-analysis. Int $J$ Eat Disord, 27, 371-380. https://doi.org/10.1002/(SICI)1098-108X (200005)27:4<371::AID-EAT1>3.0.CO;2-Y

Stice, E., \& Shaw, H. E. (2002). Role of body dissatisfaction in the onset and maintenance of eating pathology: A synthesis of research findings. Journal of Psychosomatic Research, 53(5), 985-93. https://doi.org/10.1016/S0022-3999(02)00488-9 


\section{Macrothink}

Sundgot-Borgen, J. (1993). Prevalence of eating disorders in elite female athletes. Int J Sport Nutr, 3(1), 29-40. https://doi.org/10.1123/ijsn.3.1.29

Sundgot-Borgen, J. (1994). Risk and trigger factors for the development of eating disorders in female elite athletes. Medicine \& Science in Sports \& Exercise, 26(4), 414-419. https://doi.org/10.1249/00005768-199404000-00003

Sundgot-Borgen, J., \& Torstveit, M. K. (2004). Prevalence of eating disorders in elite athletes is higher than in the general population. Clinical Journal of Sport Medicine, 14(1), 25-32. https://doi.org/10.1097/00042752-200401000-00005

Thiemann, P., Legenbauer, T., Vocks, S., Platen, P., Auyeung, B., \& Herpertz, S. (2015). Eating disorders and their putative risk factors among female German professional athletes. European Eating Disorders Review, 23(4), 269-76. https://doi.org/10.1002/erv.2360

Torstveit, M., Rosenvinge, J., \& Sundgot-Borgen, J. (2008). Prevalence of eating disorders and the predictive power of risk models in female elite athletes: A controlled study. Scandinavian Journal of Medicine \& Science in Sports, 18(1), 108-18. https://doi.org/ 10.1111/j.1600-0838.2007.00657.x

Tylkaa, T. L., \& Wood-Barcalowb, N. L. (2015). What is and what is not positive body image? Conceptual foundations and construct definition. Body Image, 14, 118-129. https://doi.org/ 10.1016/j.bodyim.2015.04.001

\section{Copyright Disclaimer}

Copyright for this article is retained by the author(s), with first publication rights granted to the journal.

This is an open-access article distributed under the terms and conditions of the Creative Commons Attribution license (http://creativecommons.org/licenses/by/3.0/). 